\title{
V1 Vasopressin Receptor Antisense Oligodeoxynucleotide into Septum Reduces Vasopressin Binding, Social Discrimination Abilities, and Anxiety-Related Behavior in Rats
}

\author{
Rainer Landgraf, ${ }^{1}$ Rüdiger Gerstberger, ${ }^{2}$ Alexandra Montkowski, ${ }^{1}$ Joseph C. Probst, ${ }^{1}$ Carsten T. Wotjak, ${ }^{1}$ \\ Florian Holsboer, ${ }^{1}$ and Mario Engelmann ${ }^{1}$ \\ 'Max Planck Institute of Psychiatry, Clinical Institute, Munich, Germany and ${ }^{2}$ Max Planck Institute of Physiological \\ and Clinical Research, Bad Nauheim, Germany
}

\begin{abstract}
To develop and validate a vasopressin (AVP) receptor knockdown strategy, we infused an antisense oligodeoxynucleotlde to the V1 subtype mRNA Into the septum of male rats with osmotic minipumps and measured behavioral, cellular and molecular parameters. Compared to vehicle and scrambled-sequence oligo controls, chronic antisense administration for up to $4 \mathrm{~d}$ diminished the ability of the animals to distinguish a previously exposed juvenile from a novel one and to respond to exogenous AVP ( $1 \mathrm{ng} / 5$ $\mu \mathrm{l}$, intracerebroventricular) with an improved social memory. Furthermore, anxiety-related behavior was reduced. As measured in the behaviorally tested rats, antisense treatment resulted in a reduced binding of radiolabeled AVP in the septum, but not in other limbic brain areas (receptor autoradiography), and an increased amount of V1 receptor mRNA (reverse transcriptase PCR), indicating translational arrest and ongoing transcriptional activity. In sense oligo-treated rats, on the other hand, both the social and the anxiety-related behavior scores lay between levels obtained in control and antisense-treated animals. These sense-treated rats showed a slightly reduced $V 1$ receptor density in the septum and reduced receptor mRNA levels, indicating hybridization of the sense oligo to the DNA. The data show the potential of antisense targeting to further reveal relationships between local gene expression, neuropeptide-receptor interactions in distinct brain areas, and behavioral performance.
\end{abstract}

[Key words: antisense, vasopressin receptor, septum, PCR, autoradiography, behavior, social discrimination, anxiety]

Vasopressin (AVP) is released within the septum of the rat brain both under basal conditions and in response to various stimuli (Landgraf et al., 1988, 1991, 1992). Following its septal release, endogenous AVP stimulates intracellular signaling mechanisms, including hydrolysis of inositol phospholipids and mobilization of calcium, through an interaction with V1 AVP receptors (Jard et al., 1987; Shewey and Dorsa, 1988). Recently, the cDNA

\footnotetext{
Received Oct. 11, 1994; revised Jan. 17, 1995; accepted Feb. 1, 1995.

We thank J. Ganster and P. Lörscher for expert assistance. This work was supported by VW.

Correspondence should be addressed to Dr. R. Landgraf, Max Planck Institute of Psychiatry, Clinical Institute, Kraepelinstrasse 2-10, D-80804 Munich, Germany.

Copyright (C) 1995 Society for Neuroscience $0270-6474 / 95 / 154250-09 \$ 05.00 / 0$
}

encoding this AVP receptor subtype was cloned (Morel et al., 1992) and its mRNA was detected in many brain areas, including the septum (Ostrowski et al., 1992). Ligand-V1 receptor interactions in this limbic brain area finally result in a variety of central effects, such as modulation of neuronal electrical activity (Disturnal et al., 1987), an increase in catecholamine turnover (Kovacs et al., 1979), antipyresis (Pittman et al., 1988), and improvement of an olfactory-cued type of social recognition (Dantzer et al., 1988). The latter paradigm in particular has been useful in studies of the role of endogenous AVP in behavioral regulation. This simple and ethologically relevant test, which has recently been modified so that it is more challenging and objective (Engelmann et al., 1995), is based on variations in the duration of social investigation of previously exposed and novel juveniles by an adult rat as an index of social discrimination abilities and memory.

Past studies on the physiological impact of AVP-receptor interactions in the septum have focused mainly on administration of V1 receptor antagonists. Although the "Manning compound" $\mathrm{d}\left(\mathrm{CH}_{2}\right)_{5}$ Tyr(Me)AVP in particular is an excellent tool for blocking these interactions, AVP antagonists gencrally are likely to cross-react with oxytocin receptors at a high dose, thus also preventing behavioral effects of oxytocin (Di Scala-Guenot et al., 1990). Furthermore, recent findings indicating that central oxytocin receptors have high affinity not only for the V1 antagonist but also for AVP (Audigier and Barberis, 1985; Roozendaal et al., 1992; Poulin and Pittman, 1993) raise the possibility that some of the actions of septal AVP mentioned earlier are in fact mediated via oxytocin receptors. Along the same lines, central effects of AVP on certain memory functions can be blocked with $\mathrm{V} 1$ as well as with $\mathrm{V} 2$ and oxytocin receptor antagonists (de Wied et al., 1991; but see Popik et al., 1992). Hence, although both septal AVP (Dantzer and Bluthé, 1993; Engelmann and Landgraf, 1994) and oxytocin (Popik et al., 1992; Witt et al., 1992) are believed to be critically involved in olfactory-cued social recognition, a precise differentiation of their receptor-mediated activity probably cannot be achieved by conventional methods of antagonist or agonist administration. The situation is further complicated by the fact that it is often difficult to distinguish between a specific blockade of a receptor-mediated effect and intrinsic effects of an antagonist (Diamant et al., 1994).

A novel approach to discriminate among closely related receptor subtypes is treatment with an antisense oligodeoxynucleotide which targets a specific receptor mRNA. Recent studies have demonstrated the efficacy of antisense treatment in down- 
Table 1. Sequences of the V1 AVP receptor mRNA, the antisense (AS), sense (S), and scrambled sequence (SS) oligodeoxynucleotides

\begin{tabular}{ll}
\hline mRNA & 5'-GUA CGG ACA GCA UGA GUU UCC-3' \\
AS & 5'-GGA AAC TCA TGC TGT CCG TAC-3' \\
S & 5'-GTA CGG ACA GCA TGA GTT TCC-3' \\
SS & 5'-CAT GTT CCA AGT GGT AAT CCG-3'
\end{tabular}

regulating receptor protein synthesis and interfering with function (McCarthy et al., 1993a,b, 1994; Wahlestedt et al., 1993; Ogawa et al., 1994; Zhou et al., 1994). Therefore, in the present study we used an antisense oligo to the $\mathrm{V} 1$ receptor subtype mRNA to examine whether its administration directly into the rat septum (1) results in altered septal V1 receptor density and levels of V1 receptor mRNA, (2) interferes with the ability of adult male rats to recognize conspecific juveniles and (3) changes anxiety-related behavior that may be associated with social interaction.

\section{Materials and Methods}

Animals

Subjects were adult male Wistar rats (Charles River, Germany) weighing an average of $350 \mathrm{gm}$ at the time of surgery. They were individually housed in standard cages with ad libitum access to tap water and laboratory chow on a $12 \mathrm{hr}$ light-dark cycle (lights on 06:00), at a temperature of $21^{\circ} \mathrm{C}$. Juveniles of the same strain (20-27 d old, both sexes) were used as social stimuli.

\section{Pump-tubing-cannula device}

For continuous infusion into the septal area, each rat was implanted with a minipump-tubing-cannula device, which was assembled prior to surgery and consisted of three parts: (1) an osmotic minipump (nominal infusion rate, $0.5 \mu 1 / \mathrm{hr}$; Alzet model 1007D), (2) an $11 \mathrm{~cm}$ length of polyethylene tubing (PE 800-100-200, Portex Ltd., England) formed as a loop, and (3) an angled 27 gauge stainless steel cannula. The pump was filled with sterilized Ringer's ( $\mathrm{pH} 7.4$ ) and both the cannula and tubing were filled with $50 \mu \mathrm{l}$ of one of the following solutions: vehicle (sterilized Ringer's, $\mathrm{pH}$ 7.4) or vehicle containing the scrambled-sequence $(0.5 \mu \mathrm{g} / \mu \mathrm{l})$, the sense $(0.5 \mu \mathrm{g} / \mu \mathrm{l})$ or the antisense oligodeoxynucleotide $(0.5 \mu \mathrm{g} / \mu \mathrm{l})$. Once filled, the tubing-cannula assembly was joined to the pump. A small air bubble was inserted to separate the infused solution from the pump's Ringer and to have a convenient index of successful infusion at the end of the experiment.

\section{Oligodeoxynucleotides}

The sequence of the 21-bases endcapped phosphorothioate antisense oligodeoxynucleotide used in this study, was designed according to the primary structure of the mRNA which codes for the V1 AVP receptor (Morel et al., 1992) and was constructed to target a region of the mRNA that flanks the initiation codon (Table 1). Corresponding vehicle as well as scrambled sequence and sense oligodeoxynucleotides (Table 1) served as controls. Neither oligonucleotide shows internal complementarity nor resembles any other known sequence after computer database scarch. Custom synthesis was performed at Genzentrum (Martinsried, Germany). Gel-filtrated and HPLC-purified oligos were dissolved in sterilized vehicle (Ringer's, $\mathrm{pH} 7.4$ ) and stored at $-20^{\circ} \mathrm{C}$.

\section{Surgery}

The cannula was lowered into the right mediolateral septum of halothane-anesthetized rats (implantation coordinates: $0.3 \mathrm{~mm}$ anterior to bregma, $2.2 \mathrm{~mm}$ lateral to midline, angle of $23^{\circ}$ to avoid damage to the sagittal sinus, depth of $6.3 \mathrm{~mm}$, Paxinos and Watson, 1986). Additionally, a 21 gauge thin-walled stainless steel guide cannula for intracerebroventricular (i.c.v.) infusion was placed with its tip over the left lateral ventricle. Both the implanted cannula assembly and the guide cannula were secured to the skull with two stainless steel screws and

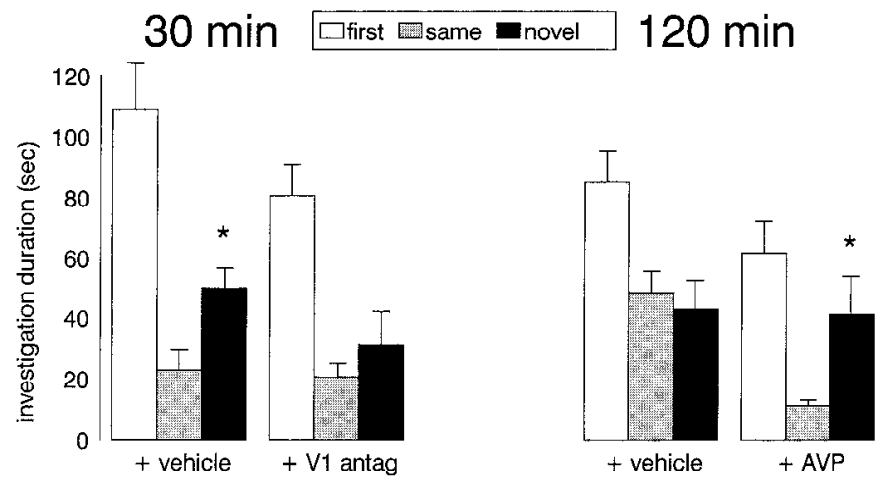

Figure 1. Social discrimination paradigm. Control rats, administered with vehicle into their septum via osmotic minipumps, investigated a conspecific juvenile during the first exposure (investigation duration in sec; white bars). Immediately thereafter, they received intracerebroventricular either vehicle, the V1 antagonist (100 ng) or $\Lambda \mathrm{VP}$ ( $1 \mathrm{ng} ; n=$ 3 each). After an interexposure interval of $30 \mathrm{~min}$ or $120 \mathrm{~min}$, both the previously exposed (dotted bar) and a novel (solid bar) juvenile were exposed to the adult. Mean + SEM; *, $p<0.05$ compared to the investigation duration towards the previously exposed juvenile.

dental cement. The osmotic minipump was placed between the scapulae in a small subcutaneous cavity. The incision was closed with metal clips and the rats were then allowed to recover under a heat lamp until they regained consciousness. To prevent infections, all steps were carried out with aseptic technique and all animals were subcutaneously injected with Tardomycel (Bayer, Germany).

\section{Behavioral tests}

Social discrimination. Prior to being tested in the recently developed social discrimination paradigm (Engelınam et al., 1995) on the evening (1800-2200) of day 3 and 4 after implantation, the adult rats were kept individually for at least $8 \mathrm{hr}$. Briefly, the animals were exposed in their home cages to a conspecific juvenile; this 4 min exposure was followed $30 \mathrm{~min}$ or $120 \mathrm{~min}$ later by a second $4 \mathrm{~min}$ exposure to the previously exposed (same) as well as to a novel juvenile. This experimental design provides the advantage that specific (i.e., juvenile-related) discrimination abilities are measurable under quite identical conditions. The corresponding durations of investigation provide an index of social, juvenile-related memory; they consisted mainly of anogenital sniffing and close-following of the juvenile. During each exposure, social investigation was measured independently by two trained observers (who were blind to the treatment) by typing preset keys on the keyboard of a computer. Between the two successive presentations, juveniles were kept individually in a small cage.

First of all we had to verify that our experimental conditions do not interfere with social discrimination abilities. According to Figure 1, animals which received vehicle via the osmotic minipumps were given additionally intracerebroventricular vehicle $(5 \mu \mathrm{l}$ infused over a $1 \mathrm{~min}$ period) immediately after the first exposure on day 3 and either the $\mathrm{V} 1$ AVP receptor antagonist $\mathrm{d}\left(\mathrm{CH}_{2}\right)_{5}$ Tyr (Me)AVP $(100 \mathrm{ng} / 5 \mu \mathrm{l}$, Dr. M. Manning, Toledo, OH) or synthetic AVP (1 ng/5 $\mu \mathrm{l}$, Ferring, Sweden; $n=3$ each) on day 4 (interexposure interval $30 \mathrm{~min}$ and $120 \mathrm{~min}$, respectively). To examine the effects of oligo treatment on behavioral performance, animals treated septally with vehicle $(n=11)$, scrambledsequence $(n=9)$, sense $(n=10)$ and antisense $(n=11)$, as shown in Figure 2, were tested on the evening of day 3 ( $30 \mathrm{~min}$ interexposure interval). After the first exposure on the following day, some of them (vehicle, $n=5$; sense, $n=7$; antisense, $n=5$ ) were infused intracerebroventricularly over a $1 \mathrm{~min}$ period with synthetic AVP $(1 \mathrm{ng} / 5 \mu \mathrm{l})$ and exposed to both the same and a novel juvenile $120 \mathrm{~min}$ later (Fig. 3).

Elevated plus-maze. Between 0900 and 1100 on the 4th day after implantation, consequences of continuous septal infusion of either vehicle $(n=14)$ or different oligos (scrambled sequence, $n=5$; sense, $n=9$; antisense, $n=12$ ) on basal plus-maze performance which is indicative of anxiety-related behavior (Handley and McBlane, 1993) were tested once in the rats. This test bases on the natural conflict of the rat to explore or to avoid exploration of elevated, open and novel 

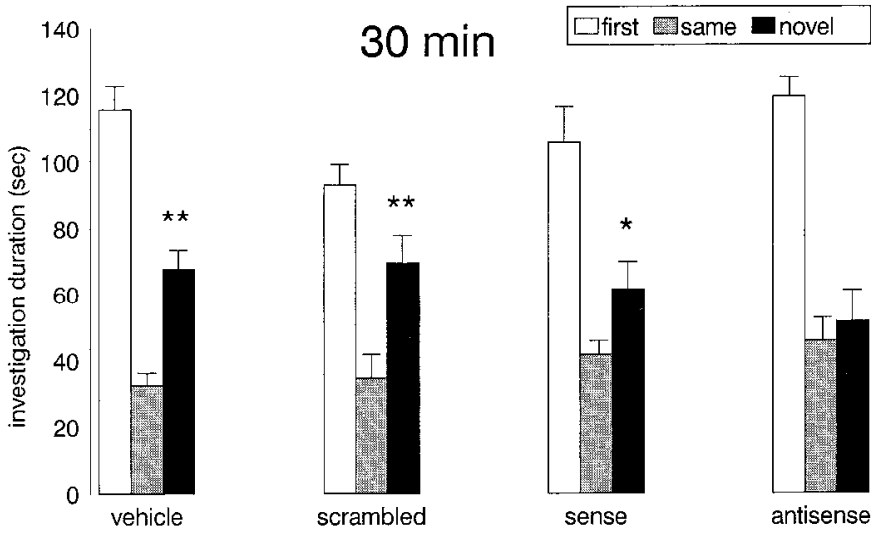

Figure 2. Investigation duration (sec; mean + SEM) of adult rats toward conspecific juveniles. The adults were administered intraseptally via osmotic minipumps with vehicle $(n=11)$, scrambled-sequence $(n$ $=9)$, sense $(n=10)$ and antisense oligos $(n=11)$, respectively; 30 min after the first exposure (white bars), both the previously exposed (dotted bars) and a novel (solid bars) juvenile had to be discriminated. **, $p<0.01 ; *, p<0.05$ compared to the investigation duration towards the previously exposed juvenile.

spaces. Briefly, the maze consisted of four arms arranged in the shape of a plus sign. Two of the opposing arms had no side walls. The other two arms were closed with side and end walls, but open at the top. The four arms intersect at the center onto a $10 \mathrm{~cm}$ square platform. The animals were individually placed onto the center platform of the maze facing a closed arm. The $5 \mathrm{~min}$ test sessions were recorded by video and behavior was subsequently scored by a trained observer blind to treatment conditions. The following measures were taken: (1) open-arm entries (expressed as percentage ratio of entries into open arms: total entries; an entry is defined as the placing of a minimum of the two forepaws into an arm), (2) percentage time spent on open arms (the smaller the time, the more anxious the rat), (3) overall activity (as reflected by the number of entries into closed arms). To reduce any lingering olfactory cues, faeces/urine were removed and the maze was thoroughly cleaned between successive tests.

\section{Histology, receptor autoradiography, RNA analysis}

After behavioral testing (i.e., immediately after the second social discrimination test), the rats were slightly anesthetized with halothane and decapitated. Brains were quickly removed and either (1) fixed in $3 \%$ formalin for subsequent histological verification of the infusion site (all rats treated with intracerebroventricular AVP), or (2) were frozen on dry ice and prepared for receptor autoradiography, or (3) septal brain areas were dissected from the fresh brain and frozen in liquid nitrogen for $\mathrm{V} 1$ receptor mRNA analysis.

Receptor autoradiography. The frozen brains from vehicle-, scrambled-sequence-, sense-, and antisense oligo-treated rats $(n=3$ each) were mounted onto cryostat chucks, and serial coronal sections of 24 $\mu \mathrm{m}$ cut at $-20^{\circ} \mathrm{C}$ (Frigocut 2700 , Reichert-Jung, Germany), thawmounted onto slides coated with poly-L-lysine (Sigma, Germany), desiccated at $-5^{\circ} \mathrm{C}$ for $5-8 \mathrm{hr}$ and stored at $-24^{\circ} \mathrm{C}$ in sealed boxes for up to 3 weeks (Gerstberger and Fahrenholz, 1989). Sections for in vitro receptor autoradiography were preincubated for $20 \mathrm{~min}$ at room temperature in $30 \mathrm{~mm}$ Tris/ $\mathrm{HCl}, \mathrm{pH} 8.0,20 \mathrm{~mm} \mathrm{NaCl}, 200 \mathrm{~mm}$ sucrose, 10 mM $\mathrm{MgCl}_{2}, 10^{-4} \mathrm{M}$ phenylmethylsulfonylfluoride (Sigma) and $0.1 \%$ BSA (RIA-grade V, Sigma). Incubation was subsequently carried out in fresh buffer for $60 \mathrm{~min}$ at room temperature with $3 \mathrm{nM}{ }^{3} \mathrm{H}-\mathrm{AVP}(75 \mathrm{Ci} /$ mmol; New England Nuclear-Du Pont, Germany). Nonspecific binding was determined in the presence of $10^{-6} \mathrm{M}$ unlabeled AVP. After incubation, the sections were transferred through three 2 min washes at $2^{\circ} \mathrm{C}$ using BSA-free Tris/HCl buffer, dipped in distilled water and rapidly dried in a stream of cold air. Dried sections were juxtaposed against a sheet of tritium-sensitive $\beta_{\max }$-hyperfilm (Amersham, Germany) for 35 $\mathrm{d}$. Brain areas bearing binding sites specific for the radioligand were determined according to the stereotaxic coordinates (Paxinos and Watson, 1986). Quantitative receptor autoradiography was performed by computerized densitometry (RAG-200; BioCom, France) in various brain regions. Optical densities were calibrated with coexposed stan-

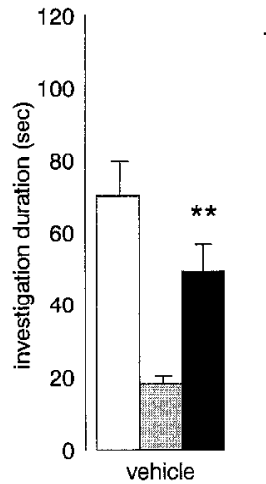

+ AVP, $120 \min$

$\square$ first

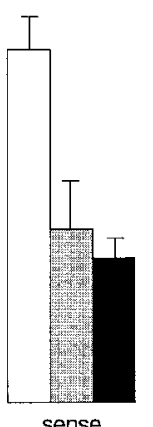

sense

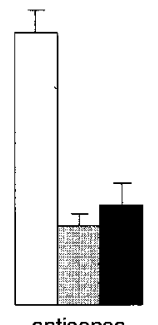

Figure 3. Investigation duration (sec; mean + SEM) of adult rats towards conspecific juveniles. The adults were intraseptally infused via osmotic minipumps with vehicle $(n=5)$, sense $(n=7)$, and antisense oligos $(n=5)$, respectively. Immediately after the first exposure (white bars), they received intracerebroventricular $1 \mathrm{ng}$ AVP; $120 \mathrm{~min}$ later they were exposed to both the previously exposed (dotted bars) and a novel (solid bars) juvenile. ${ }^{* *}, p<0.01$ compared to the investigation duration toward the previously exposed juvenile.

dards revealing brain substance-like quench coefficients for tritiated isotopes (Amersham) and converted to $\mathrm{fmol} / \mathrm{mg}$ protein of radioligand bound. Measurements were obtained either in the absence (total binding) or presence of $10^{-6} \mathrm{M}$ unlabeled AVP (nonspecific binding).

RNA isolation and PCR analysis. RNA was isolated from dissected septal areas (vehicle, $n=2$; scrambled sequence, $n=3$; sense, $n=3$; antisense, $n=8$ ) by the guanidinium isothiocyanate protocol (Chirgwin et al., 1979; Chomczynski and Sacchi, 1987). Samples were mechanically homogenized and processed as described. Briefly, RNA extracts (1 $\mu \mathrm{g}$ total RNA) were reverse transcribed with a 16-mer oligo-dT primer and reverse transcriptase, according to the manufacturers protocol (Perkin Elmer, Germany). Thermoenzymatic amplification was performed in a Hybaid thermocycler, using the primers V1-1 d(GGCTTTTGGTTACACCTTG) and V1-2 d(GAAGTCTGTCTTTCGGCTC) with 28 cycles. The amplification product was analyzed with agarose gel electrophoresis, followed by Southern Blot. Blots were hybridized with digoxigenin-labeled oligonucleotide V1-3 d(CCTACATCCTTTGCTGGG) corresponding to the bases $911-928$ of the V1 receptor mRNA. Conditions for prehybridization, hybridization and posthybridization washes were as described by Engler-Blum et al. (1993). Chemiluminescence detection was made on Kodak XOMAT X-ray films after $1 \mathrm{hr}$ exposure. As a control, to ensure that the same amount of cDNA was used in all amplification experiments, the cDNA encoding $\beta$-actin was amplified with specific oligonucleotides (Nudel et al., 1983) generating a product of 260 base pairs.

\section{Statistics}

Results are expressed as means + SEM. For statistical analysis of the behavioral data in the social discrimination paradigm, a three-way ANOVA (groups $\times$ sessions $\times$ juvenile) with repeated measures on the last two factors or a two-way ANOVA (groups $\times$ juvenile) with repeated measures on the last factor were used. Data obtained in both the elevated plus-maze (analyzed separately for each parameter) and from receptor autoradiography were analyzed using completely randomized ANOVAs. Post hoc comparisons were made using Tukey's HSD test. Significance was accepted if $p<0.05$.

\section{Results}

Precise placement of infusion cannulae in the right mediolateral septum was validated histologically in all rat brains treated with intracerebroventricular AVP. The light microscopic appearance of the tissue in the surroundings of the infusion site was normal, regardless of whether vehicle or oligos were administered.

On day 3 after implantation, control animals which received vehicle into their septum via osmotic minipumps were able to recognize the previously exposed juvenile (three way ANOVA, factors: sessions; overall performance: $F_{1,4}=20.32, p=0.011$; 


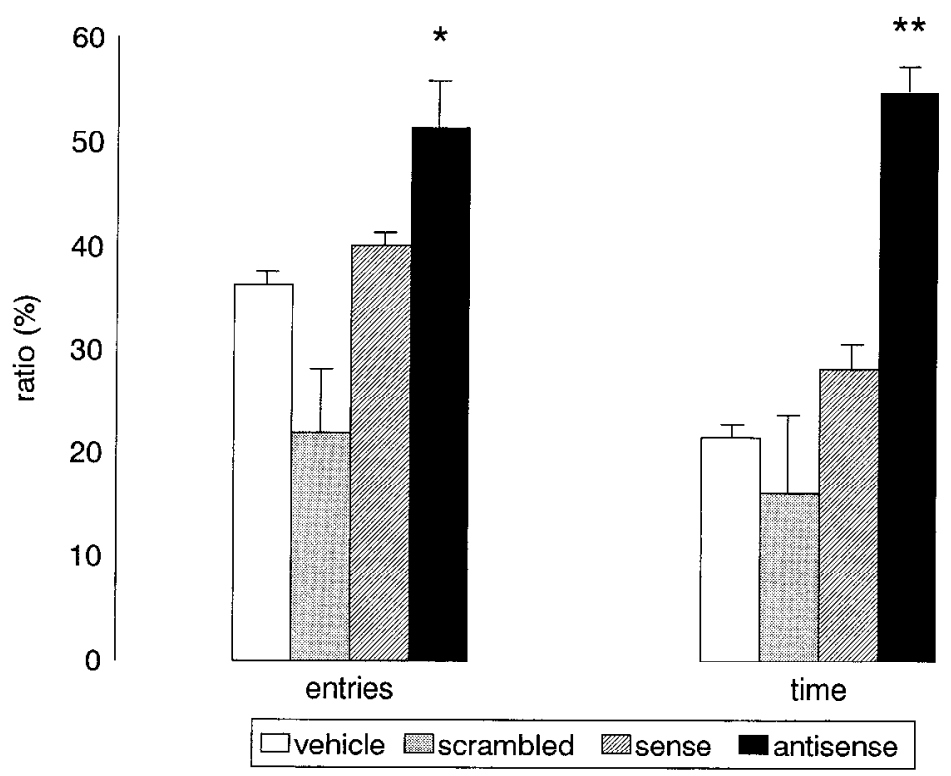

Figure 4. Anxiety test using the elevated plus-maze. The rats were intraseptally infused via osmotic minipumps with vehicle $(n=14)$, scrambled sequence $(n=5)$, sense $(n=9)$ and antisense oligos $(n=12)$, respectively. Parameters measured: open-arm entries (percentage ratio of entries into open arms: total entries) and percentage time spent in open arms. Mean + $\mathrm{SEM} ;{ }^{* *}, p<0.01$ compared to all the other groups; *, $p<0.05$ compared to vehicle and scrambled sequence controls.

juveniles: $F_{1,4}=15.79, p=0.017$; interaction: $F_{1,4}=7.45, p$ $=0.050$ ). During the second exposure, $30 \mathrm{~min}$ after the first one, a simultaneously exposed novel juvenile was significantly longer investigated ( $p<0.05$; Fig. 1). Immediately after the first exposure on the following day, the animals were administered intracerebroventricularly with $100 \mathrm{ng}$ of the V1 antagonist. This treatment resulted in a clear inability of the adults to distinguish between both juveniles after an interexposure interval of $30 \mathrm{~min}$ (Fig. 1). In another group of vehicle-treated rats, we showed that, $120 \mathrm{~min}$ after the first exposure, the animals were no longer able to discriminate between both juveniles. Intracerebroventric ular injection of $1 \mathrm{ng}$ of AVP after the first exposure on the following day, however, enabled these animals to recognize the familiar juvenile even after this long interexposure interval ( $p$ $<0.05$; Fig. 1).

For the animals which were septally treated with vehicle or oligodeoxynucleotides, the two-way ANOVA with repeated mcasurcs on the last factor showed a significant interaction $\left(F_{3,38}\right.$ $=3.54 ; p=0.024 ;$ Fig. 2 ). Administration of the antisense oligo to the V1 receptor mRNA over a $3 \mathrm{~d}$ period significantly interfered with the ability of the animals to recognize the previously exposed juvenile as during the second exposure, $30 \mathrm{~min}$ after the first one, both the same and a novel juvenile were similarly investigated (Fig. 2). In contrast, the behavioral performance of scrambled-sequence oligo-treated controls resembled that of vehicle-treated animals in that they displayed a marked decrease $(p<0.01)$ in investigation time of the previously presented juvenile. Interestingly, sense oligo-treated rats, although being able to recognize the familiar juvenile $(p<0.05)$, tended to have lower discrimination capabilities than vehicle- and scrambled-sequence-treated animals (Fig. 2). This became even more evident on the following day when animals, in addition to their septal treatment, received $1 \mathrm{ng}$ AVP i.c.v. immediately after the first exposure (interaction: $F_{2,15} \cdots 74.42, p<0.001$ ). In contrast to vehicle-treated rats $(p<0.01)$, the social discrimination capability of both sense- and antisense-treated animals was not improved, that is, sense and antisense oligos administered into the septum similarly interfered with the behavioral effect of the exogenous neuropeptide (Fig. 3).

Chronic infusion of antisense oligos into the septum via os- motic minipumps resulted in signs of a significantly reduced anxiety-related behavior. As shown in Figure 4, the rats had an increased number of open-arm entries compared to vehicle- and scrambled sequence-treated animals $\left(F_{3,36}=4.96, p=0.005 ; p\right.$ $<0.05$ and $p<0.01$, respectively). In addition to having more entries, animals of the antisense group spent more time on the open arms of the elevated plus-maze than animals of both control groups $\left(F_{3,36}=5.57 ; p=0.003\right)$ which did not differ from each other. Sense oligo-treated rats lay between control and antisense animals (Fig. 4). Furthermore, no significant differences among the groups were observed in overall activity, although antisense-treated rats tended to be less active than controls (data not shown).

Following decapitation of the rats after their last behavioral test, whole brains or septal areas were analyzed by receptor autoradiography and RNA analysis, respectively. As shown in Figure 5 , the specific binding of ${ }^{3} \mathrm{H}-\mathrm{AVP}$ (fmol/mg protein) revealed a significant interaction in the lateral septum (medial: $F_{3,8}-$ 10.67, $p=0.004$; dorsal: $F_{3,8}=4.97, p=0.031$ ), but not in the central nucleus of the amygdala $\left(F_{3,8}=1.49, p=0.280\right)$ and the bed nucleus of the stria terminalis (BNST; $F_{3,8}=1.49$, $p=0.280$ ). Antisense oligo treatment resulted in a reduced receptor density in the lateral septum compared to both vehicle and scrambled sequence controls $(p<0.01$ and $p<0.05$, respectively). Again, in sense oligo-treated animals, this parameter lay between that of antisense and control rats (Figs. 5, 6). Although in the amygdala and BNST ${ }^{3} \mathrm{H}$-AVP binding did not differ among the groups, it should be noted that antisense treatment tended to lower receptor density in both limbic brain areas (Fig. 5).

RNA analysis via reverse transcriptase PCR (RT-PCR) clearly demonstrated that after infusion of antisense oligo into the rat septum the $V 1$ receptor mRNA levels were markedly increased when compared to those of vchicle- and scrambled-scquence oligo-infused animals. Interestingly, the sense oligo-treated rats revealed a reduction in V1 receptor mRNA (Fig. 7A,B). Possible RNA content fluctuations of the RNA preparations can be excluded, since the $\beta$-actin RT-PCR, under identical experimental conditions, consistently yielded equal amounts of PCR-product (Fig. 7C). 


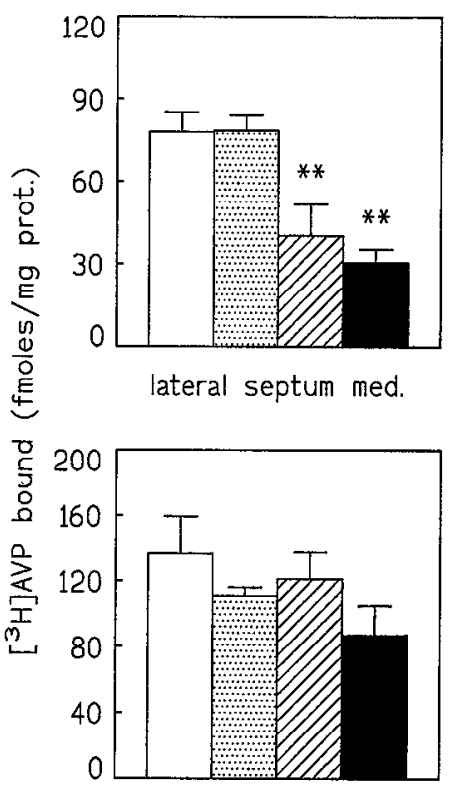

central amygdala
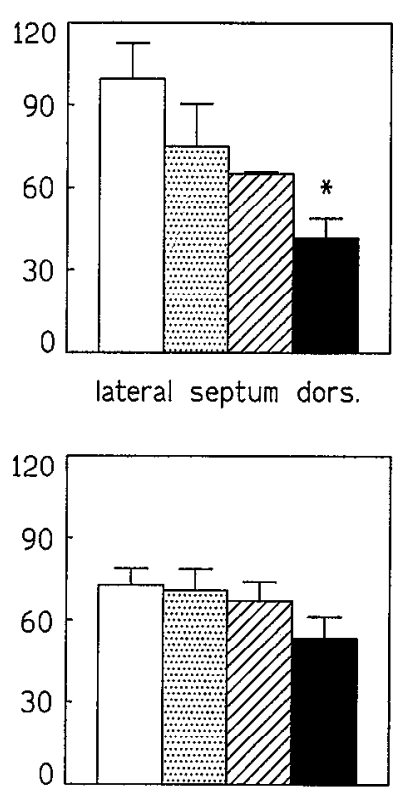

BNST

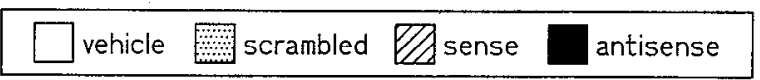

Figure 5. Specific binding of ${ }^{3} \mathrm{H}$-AVP (fmol/mg protein) to limbic structures of the rat brain (medial and dorsal area of the lateral septum; central nucleus of the amygdala; bed nucleus of the stria terminalis, $B N S T$ ). Binding was performed in rats which had received chronic intraseptal administration of vehicle, scrambled-sequence, sense, and antisense oligodeoxynucleotides ( $n=3$ each), respectively. Mean + SEM; ${ }^{* *}, p<0.01$ compared to vehicle and scrambled sequence; $*, p<0.05$ compared to all the other groups.

\section{Discussion}

Intraseptal administration of an antisense oligodeoxynucleotide to the mRNA for the VI AVP receptor subtype reduced binding of radiolabeled AVP in the septum, but not in other limbic brain areas, and increased receptor mRNA levels, indicating local translational arrest and ongoing transcriptional activity. As determined in the same animals, antisense treatment significantly (1) interfered with the ability of the rats to recognize juveniles in the social discrimination paradigm and (2) enhanced entries into the open arms of the plus-maze and prolonged the time spent there, indicating that both the deficit in social memory and the relief of anxiety have cellular and molecular correlates. The comparison between vehicle and scrambled-sequence oligo controls argues against the possibility of antisense oligo infusions having essentially nonspecific effects such as neuronal toxicity and general disruption of protein synthesis. Taken together, these findings suggest that intraseptal administration of an antisense oligo selectively reduced synthesis of the $\mathrm{V} 1$ receptor in the infused limbic brain area and that this receptor subtype is critically involved in the regulation of social discrimination and anxiety-related behavior.

Central actions mediated by the septal AVP system are most likely the result of changes in septal AVP release rather than in receptor expression in target neurons (Fig. 1; Landgraf, 1992). Accordingly, studies on the involvement of this AVP system in behavioral regulation have, for example, used AVP-deficient animals (homozygous Brattleboro rats: Engelmann and Landgraf, 1994; castrated rats: Bluthé et al., 1990). However, in these ex-

periments many other variables not primarily related to septal AVP were affected as well. In other studies, pharmacological manipulations aimed at interfering with AVP-receptor interactions in the septum were made using synthetic AVP and V1 receptor antagonists (Dantzer et al., 1988; Engelmann and Landgraf, 1994). Although these substances have been valuable tools in determining the role of endogenous AVP, they have major drawbacks in that they cross-react also with oxytocin receptors. Thus convincing evidence for the involvement of the V1 receptor subtype in behavioral regulation is still lacking (de Wied et al., 1991, 1993). In the present study we focused on an antisense approach to downregulate selectively the V1 AVP receptor density in the rat septum. Because this strategy was being used for the first time, the techniques involved also had to be validated. Therefore, we mainly focused on a well-established paradigm, the social recognition/discrimination test (Dantzer et al., 1988; Engelmann ct al., 1995), in which an AVP-receptor interaction is thought to be causally involved (Dantzer and Bluthé, 1993). This involvement, which has now been confirmed under our experimental conditions (Fig. 1), reduced the risk of compensation for the septal deficit in AVP-receptor interactions by any other pathways.

The simultaneous contact of the adult rat with the previously exposed and a novel juvenile during the second exposure particularly challenges the discriminative capacities of the animal. The inability of antisense-treated rats to distinguish between the juveniles after an interexposure interval of $30 \mathrm{~min}$ (Fig. 2) indicates interfering consequences of a disturbed ligand-receptor interaction due to a reduced receptor density in the septum. This behavioral deficit was related to the blocked action not only of endogenous but also of exogenous AVP, as rats that were given antisense oligos failed to respond to the intracerebroventricular injection of $\Lambda V P$ (Fig. 3).

In this context it is of interest to note that both the V1 antagonist and the antisense oligo appear to have induced the inability to discriminate by decreasing the investigation duration towards the novel juvenile rather than by increasing it towards the same juveniles (Figs. 1, 3). Further studies are necessary to clarify this issue.

The findings for the vehicle-treated groups with intracerebroventricular AVP shown in Figures 1 and 3 clearly argue against the possibility that the chronic infusion into the septum per se contributed to the failure to respond to exogenous AVP, as these groups responded to the neuropeptide in a predictable manner (see Dantzer et al., 1988; Engelmann and Landgraf, 1994). Interestingly, sense oligo treatment did not actually affect social discrimination abilities, but the lower level of statistical significance (Fig. 2) led us to hypothesize that these animals behave slightly differently from vehicle- and scrambled-sequence-infused controls on the one hand and antisense-infused rats on the other, and that this becomes more evident after intracerebroventricular administration of $1 \mathrm{ng}$ of synthetic AVP. Indeed, the subsequent comparison revealed that sense-treated rats behaved like antisense-treated rats in that they failed to respond to exogenous AVP with an improved social memory (Fig. 3). These findings in sense oligo-treated animals indicate that (1) the V1 receptor synthesis in the septum was slightly diminished, (2) probably all receptor sites still available were occupied by endogenous AVP, which was sufficient to maintain the social discrimination abilities for $30 \mathrm{~min}$, and (3) no additional receptors were available that might have mediated the memory-improving effect of exogenous AVP. 


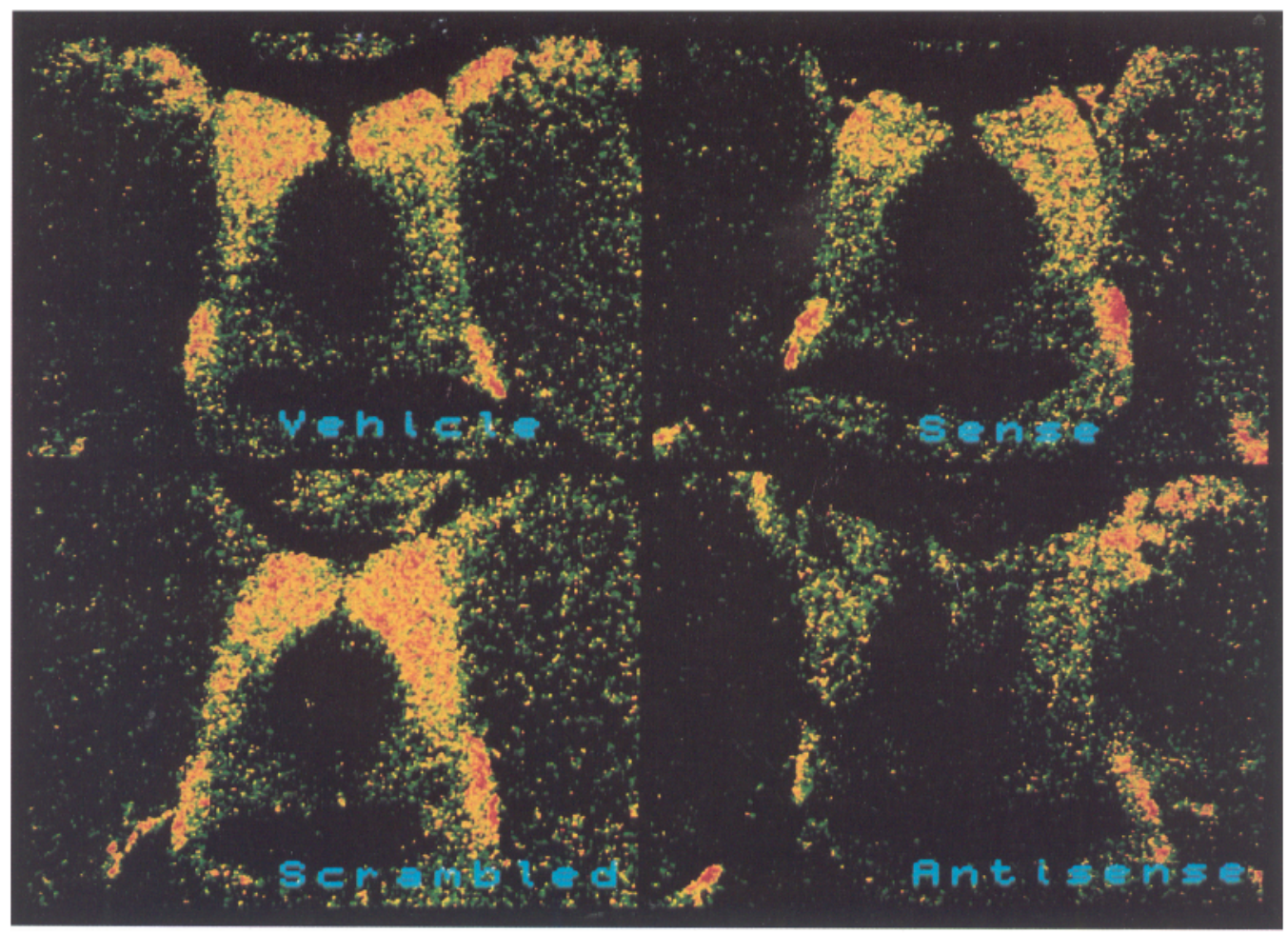

Figure 6. Pseudo-color coded receptor autoradiograms of coronal cryostat sections of the rat brain at the level of the anterior commissure. Representative ${ }^{3} \mathrm{H}$-AVP binding to the lateral septum is demonstrated for experiments with chronic intraseptal administration of either vehicle, scrambled-sequence, sense, or antisense oligodeoxynucleotides.

The present data point to the septum as a decisive target of both endogenous and exogenous AVP, mediating behavioral effects of the neuropeptide via the V1 receptor subtype. If septal V1 receptors were downregulated by antisense treatment, as shown in Figures 5 and 6, neither endogenous nor intracerebroventricular AVP would be effective (Figs. 2, 3). Generally, this limbic brain area is located in a highly strategic position as it relates learning and memory to their emotional context and translates them into motivated behavior (Thomas, 1988). Inasmuch as it has been suggested that AVP is physiologically involved in fear conditioning (Stoehr and North, 1993) and that septal lesions induce anti-fear effects (Treit et al., 1993), we also examined the consequences of $\mathrm{V} 1$ receptor downregulation in the septum on plus-maze performance, which is indicative of anxiety-related behavior (Handley and McBlane, 1993). Antisense oligo-induced effects indicate that the V1 receptor subtype which mediates improved social discrimination abilities also changes the emotionality of the animals (Fig. 4). This is compatible with an apparent decrease in anxiety-associated behavior in rats genetically unable to produce biologically active AVP (Herman et al., 1986). Nevertheless, further studies have to focus on additional receptor (sub)types which might mediate effects of endogenous AVP on anxiety.

Although the relationship between social memory and the particular emotionality is far from clear, the notion is attractive, that in the end the effects on emotion influence social memory by changing the balance between reserve and explorative curiosity. This balance, however, is certainly more important during social interaction among adult animals than during exposure to a juvenile. It is still unknown whether the inability to recognize the previously exposed juvenile and the relief of anxiety in response to antisense treatment demonstrated in this paper are causally related events. Therefore, further studies should focus on possible synergistic actions of endogenous AVP on cognitive and emotional alterations.

Taken together, the behavioral data indicated that, compared to vehicle and scrambled-sequence controls, the $\mathrm{V} 1$ receptor subtype in the septum was slightly reduced in sense- and markedly reduced in antisense-treated rats. This hypothesis was clearly confirmed by analysis of the receptor autoradiograms of the same rats that had been tested previously in the social discrimination and anxiety paradigms (Figs. 5, 6). The reduction in V1 receptor binding, which occurred in the lateral septum, but not in closely related limbic brain areas, averaged $36 \%$ in sense and $57 \%$ in antisense oligo-treated animals (Fig. 5) and is similar to or even higher than that of other receptors after antisense treatment (Wahlestedt et al., 1993; McCarthy et al., 1994; Sakai et al., 1994). Although the present data appear to reveal a more or less causal cascade of events from gene to behavior, changes at molecular, cellular, and behavioral levels should be compared with caution. Certainly not all septal V1 receptors are equally involved in behavioral regulation, and despite the critical role they play, other receptor types may additionally be involved in the regulation of social and anxiety-related behaviors. While it, therefore, does not seem appropriate to compare changes in binding with behavioral responses on a quantitative scale, our data suggest that a sufficient number of septal V1 receptors were downregulated to significantly alter social discrimination abilities and anxiety-related behavior.

Although the precise mechanisms of action of the antisense oligo have yet to be elucidated, our data suggest that its performance is based primarily on the induction of translational arrest 


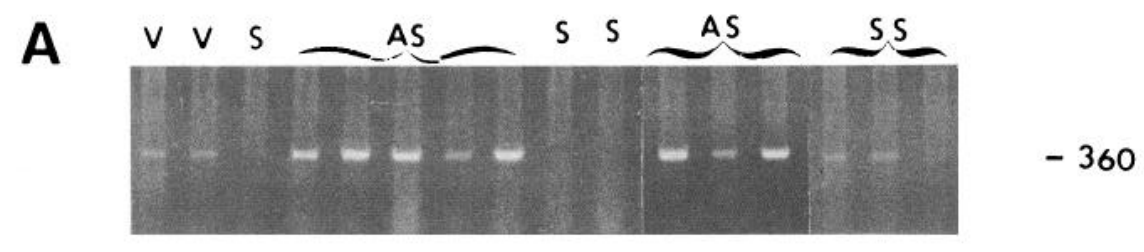

Figure 7. RT-PCR analysis of septal RNA coding for V1 receptor isolated from vehicle-treated ( $V, n=2)$, scrambled sequence oligo-treated ( $S S, n=$ $3)$, sense-treated $(S, n=3)$, and antisense-treated ( $A S, n=8)$ rats. $A$, RTPCR products, separated on an ethidium bromide stained agarose gel, of RNA templates derived from septa isolated from V-, SS-, S-, and AS-treated animals. $B$, The corresponding Southern blot after chemiluminescence detection of the $\mathrm{V} 1$ receptor cDNA after hybridization with the digoxigenin labeled oligo probe. $C$, Ethidium bromide-stained agarose gel of the control RT-PCR employing $\beta$-actin specific primers. Size marker lengths are indicated in nucleotides.
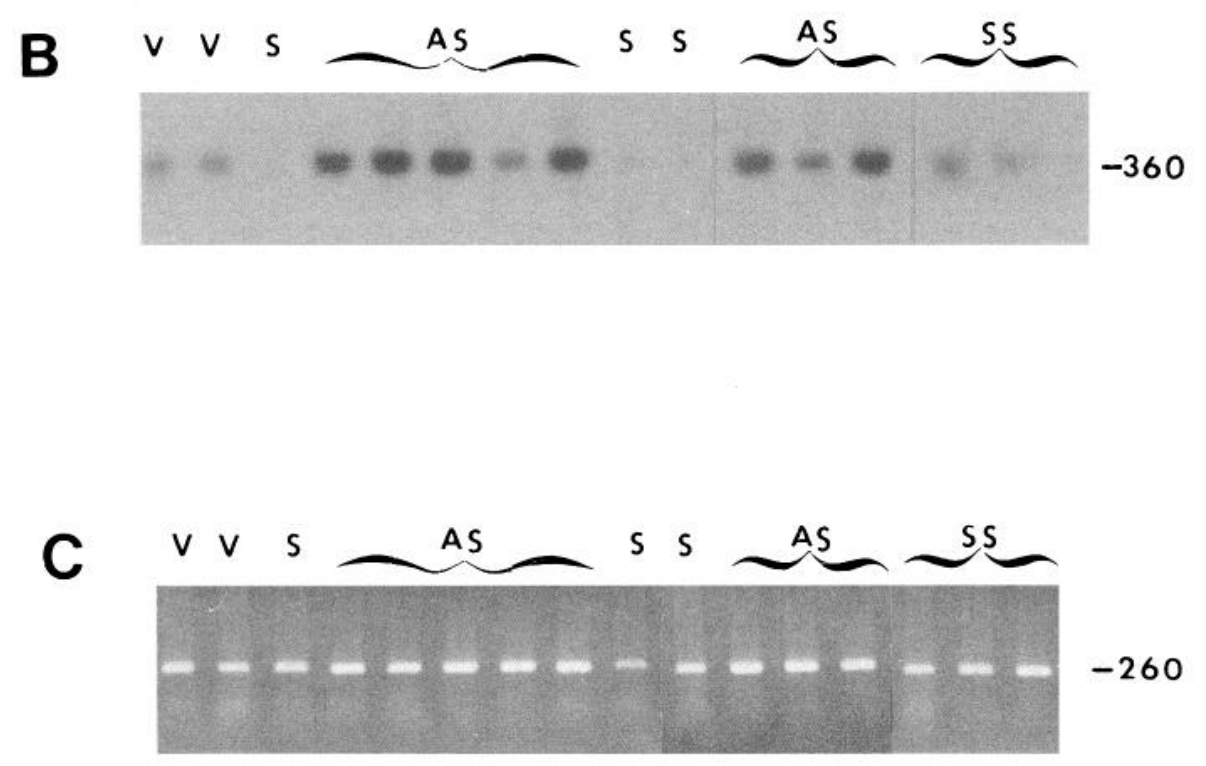

(Liebhaber et al., 1992). Contradictory to recent reports (Agrawal et al., 1991; Giles and Tidd, 1992), however, we did not see an increase in transcript breakdown. Rather, antisense effects, which resulted in a reduced receptor density and behavioral deficits, were associated with a rise in mRNA levels, indicating ongoing transcriptional activity (Fig. 7). As our molecular, cellular, and behavioral findings suggest, the sense oligo may have hybridized to double-stranded DNA, possibly forming a DNA triplex (Baertschi, 1994), and thus partially inhibiting gene expression. This would explain why treatment with the sense oligo resulted in a reduced mRNA production, a slight reduction in receptor density (more mRNA translated than in antisense-treated animals) and, consequently, a partial deficit in behavioral performance. Whatever the underlying mechanisms may be, although the sense-induced effects appear to be of rather limited value as controls, they make it possible to induce gradual alterations in V1 receptor density.

Most of the reports published hitherto used phosphorothioate oligodeoxynucleotides. This chemical modification has the advantage that derivatives are taken up by neurons and are less susceptible to nuclease degradation than their unmodified counterparts (for review, see Zhao et al., 1993; Baertschi, 1994). To maintain more stable and effective concentrations of the antisense oligo at the site of intended action than, for example, an intracerebroventricular infusion would provide, in the present experiments we infused phosphorothioate-modified oligos directly into the septum via osmotic minipumps for up to $4 \mathrm{~d}$. This mode of administration and time schedule was chosen (1) to downregulate the V1 receptor in the septum only, but not in closely related limbic brain areas (see Fig. 5), (2) to minimize the risk that the antisense treatment affects the olfactory system itself rather than those areas which are involved in processing olfactory information, (3) to allow for hybridization with the nascent mRNA (for review, see Uhlmann and Peyman, 1990), (4) to permit the elimination of preexisting V1 receptors as part of the general turnover of membrane proteins, and (5) to counteraffect possible compensatory regulations, as indicated by the increased V1 receptor mRNA in antisense-treated animals (Fig. 7). However, toxic effects of the phosphorothioate antisense oligo, which can be sequence-specific and vary in different tissues and experimental conditions, cannot be completely ruled out solely on the basis of no observed effects by scrambled-sequence oligos. Therefore, we compared the action of antisense versus scrambled-sequence oligos additionally with inverted 3 'internucleotide linkages; this modification provides protection against nucleolytic degradation (Ortigao et al., 1992). Preliminary results indicate that these inverted oligos induce effects in the social discrimination paradigm that resemble those after phosphorothioate oligo treatment (data not shown), confirming that the antisense actions described in this article are not due primarily to toxic phosphorothioate actions on cellular functions.

Recently, we used the antisense targeting technique to manipulate the synthesis/release of AVP (Skutella et al., 1994) and oxytocin (Neumann et al., 1994). Although the underlying mechanisms of action may differ from those involved in the present receptor study, these data showed that a broad variety 
of functional parameters may be influenced, including drinking behavior and milk ejection reflexes. Hence, antisense targeting certainly has the potential of interfering with AVP and AVP receptor synthesis, thus providing an alternative to antagonist administration and to recently described approaches to transient inhibition of the hypothalamic nonapeptidergic systems, including immunotoxin (Burlet et al., 1992) and cysteamine (Kwok et al., 1994) administration. The antisense oligo approach described here may also be useful in investigating other aspects of septal AVP-receptor interactions in more detail, such as the positive feedback action of AVP on its own release (Landgraf et al., 1991) and the paradoxical self-sensitization effect (Poulin and Pittman, 1993). Although more experimental evidence is needed that antisense targeting is in fact more specific than more conventional techniques, such targeting clearly has the potential of providing further insights into the molecular and cellular basis of behavioral regulation.

\section{References}

Agrawal S, Temsamani J, Tang JY (1991) Pharmacokinetics, biodistribution and stability of oligodeoxynucleotide phosphorothioates in mice. Proc Natl Acad Sci USA 88:7595-7599.

Audigier S, Barberis C (1985) Pharmacological characterization of two specific binding sites for neurohypophyseal hormones in hippocampal synaptic membranes of the rat. EMBO J 4:1407-1412.

Baertschi AJ (1994) Antisense oligonucleotide strategies in physiology. Mol Cell Endocrinol 101:R15-R24.

Bluthé RM, Schoenen J, Dantzer R (1990) Androgen-dependent vasopressinergic neurons are involved in social recognition in rats. Brain Res 519:150-157.

Burlet A, Chapleur-Chateau M, Haumont-Pellegri B, Jansen F, Menzaghi F, Fernette B, Nicolas JP, Burlet C (1992) Long-term reduction of vasopressin excretion induced by the central injection of an immunoconjugate (antibody to vasopressin linked to ricin A chain). Neuroscience 4:965-973.

Chirgwin JM, Pryzybyla AE, MacDonald RJ, Rutter WJ (1979) Isolation of biologically active ribonucleic acid from sources enriched in ribonucleases. Biochemistry 18:5294-5299.

Chomczynski P, Sacchi N (1987) Single-step method of RNA isolation by acid guanidinium thiocyanate-phenol-chloroform extraction. Anal Biochem 162:156-159.

Dantzer R, Bluthé R-M (1993) Vasopressin and behavior: from memory to olfaction. Regul Peptides 45:121-125.

Dantzer R, Koob GF, Bluthé R-M, Le Moal M (1988) Septal vasopressin modulates social memory in male rats. Brain Res 457:143147.

De Wied D, Elands J, Kovacs G (1991) Interactive effects of neurohypophyseal neuropeptides with receptor antagonists on passive avoidance behavior. Mediation by a cerebral neurohypophyseal hormone receptor? Proc Natl Acad Sci USA 88:1494-1498.

De Wied D, Diamant M, Fodor M (1993) Central nervous system effects of the neurohypophyseal hormones and related peptides. Front Neuroendocrinol 14:251-302.

Diamant M, Baars AM, Kovács GL, De Wied D (1994) Barrel rotation induced by central arginine ${ }^{8}$-vasopressin treatment: involvement of neurohypophyseal peptide receptors. Pharmacol Biochem Behav 47: 27-32.

Di Scala-Guenot D, Strosser MT, Freund-Mercier MJ, Richard P (1990) Characterization of oxytocin-binding sites in primary rat brain cell cultures. Brain Res 524:10-16.

Disturnal JE, Veale WL, Pittman QJ (1987) Modulation by arginine vasopressin of glutamate excitation in the ventral septal area of the rat brain. Can J Physiol Pharmacol 65:30-35.

Engelmann M, Landgraf R (1994) Microdialysis administration of vasopressin into the septum improves social recognition in Brattleboro rats. Physiol Behav 55:145-149.

Engelmann M, Wotjak CT, Landgraf R (1995) The social discrimination procedure: an alternative method to investigate juvenile recognition abilities in rats. Physiol Behav, in press.

Engler-Blum G, Meier M, Frank J, Müller GA (1993) Reduction of background problems in nonradioactive northern and southern blot analyses enables higher sensitivity than ${ }^{32} \mathrm{P}$-based hybridizations. Anal Biochem 210:235-244.

Gerstberger R, Fahrenholz F (1989) Autoradiographic localization of V1 vasopressin binding sites in rat brain and kidney. Eur J Pharmacol 167:105-116.

Giles RV, Tidd DM (1992) Increased specificity for antisense oligonucleotide targeting of RNA cleavage by RNase-H using chimeric methylphosphonodiester/phosphodiester structures. Nucleic Acids Res 20:763-770.

Handley SL, McBlane JW (1993) An assessment of the elevated $\mathrm{X}$-maze for studying anxiety-modulating drugs. J Pharmacol Toxicol Methods. 29:129-138.

Herman JP, Thomas GJ, Gash DM (1986) Behavioral characteristics of Roman high avoidance rats homozygous for diabetes insipidus (RHA: $\mathrm{di} / \mathrm{di})$. Behav Brain Res 20:27-38.

Jard S, Barberis C, Audigier S, Tribollet E (1987) Neurohypophyseal hormone receptor systems in brain and periphery. Prog Brain Res 72: $172-187$.

Kovacs GL, Bohus B, Versteeg DHG (1979) The effects of vasopressin on memory processes: the role of noradrenergic neurotransmission. Neuroscience 4:1529-1537.

Kwok RPS, Cameron JL, Fernstrom JD (1994) Effect of cysteamine injection on vasopressin and oxytocin biosynthesis in rat hypothalamus. Neuroendocrinology 59:218-227.

Landgraf R (1992) Central release of vasopressin: stimuli, dynamics, consequences. Prog Brain Res 91:29-39.

Landgraf R, Neumann I, Schwarzberg H (1988) Central and peripheral release of vasopressin and oxytocin in the conscious rat after osmotic stimulation. Brain Res 457:219-225.

Landgraf R, Neumann I, Pittman QJ (1991) Septal and hippocampal release of vasopressin and oxytocin during late pregnancy and parturition in the rat. Neuroendocrinology 54:378-383.

Landgraf R, Neumann I, Russell JA, Pittman QJ (1992) Push-pull perfusion and microdialysis studies of central oxytocin and vasopressin release in freely moving rats during pregnancy, parturition, and lactation. Ann NY Acad Sci 652:326-339.

Liebhaber SA. Russell JE, Cash FE, Eshleman SS (1992) Inhibition of messenger RNA translation by antisense sequences. Gene Regul $1: 163-174$.

McCarthy MM, Brooks PJ, Pfaus JG, Brown HE, Flanagan LM, Schwartz-Giblin S, Pfaff DW (1993a) Antisense oligodeoxynucleotides in behavioral neuroscience. Neuroprotocols 2:67-74.

McCarthy MM, Schlenker EH, Pfaff DW (1993b) Enduring consequences of neonatal treatment with antisense oligodeoxynucleotides to estrogen receptor messenger ribonucleic acid on sexual differentiation of rat brain. Endocrinology 133:433-439.

McCarthy MM, Kleopoulos SP, Mobbs CV, Pfaff DW (1994) Infusion of antisense oligodeoxynucleotides to the oxytocin receptor in the ventromedial hypothalamus reduces estrogen-induced sexual receptivity and oxytocin receptor binding in the female rat. Neuroendocrinology 59:432-440.

Morel A, O'Carroll A-M, Brownstein MJ, Lolait SJ (1992) Molecular cloning and expression of a rat $\mathrm{V} 1 \mathrm{a}$ arginine vasopressin receptor. Nature 356:523-526.

Neumann I, Porter DWF, Landgraf R, Pittman QJ (1994) Rapid effect on suckling of an oxytocin antisense oligonucleotide administered into the rat supraoptic nucleus. Am J Physiol 267:R852-R858.

Nudel U, Zakut R, Shani M, Levy Z, Yaffe D (1983) The nucleotide sequence of the rat cytoplasmic beta-actin gene. Nucleic Acids Res 11:1759-1771.

Ogawa S, Olazabal UE, Parhar IS, Pfaff DW (1994) Effects of intrahypothalamic administration of antisense DNA for progesterone receptor mRNA on reproductive behavior and progesterone receptor immunoreactivity in female rat. J Neurosci 14:1766-1774.

Ortigao JFR, Rösch H, Selter H, Fröhlich A, Lorenz A, Montenarh M, Seliger H (1992) Antisense effect of oligodeoxynucleotides with inverted terminal internucleotidic linkages: a minimal modification protecting against nucleolytic degradation. Antisense Res Dev 2:129146.

Ostrowski NL, Lolait SJ, Bradley DJ, O'Carroll A-M, Brownstein MJ, Young WS (1992) Distribution of V1a and V2 vasopressin receptor messenger ribonucleic acids in rat liver, kidney, pituitary and brain. Endocrinology 131:533-535.

Paxinos G, Watson C (1986) The rat brain in stereotaxic coordinates. Sydney: Academic. 
Pittman QJ, Naylor A, Poulin P, Disturnal J, Veale WL, Martin SM, Malkinson TJ, Mathieson B (1988) The role of vasopressin as an antipyretic in the ventral septal area and its possible involvement in convulsive disorders. Brain Res Bull 20:887-892.

Popik P, Vos PE, van Ree JM (1992) Neurohypophyseal hormone receptors in the septum are implicated in social recognition in the rat. Behav Pharmacol 3:351-358.

Poulin P, Pittman QJ (1993) Oxytocin pretreatment enhances arginine vasopressin-induced motor disturbances and arginine vasopressin-induced phosphoinositol hydrolysis in rat septum: a cross-sensitization phenomenon. J Neuroendocrinol 5:33-39.

Roozendaal B, Wiersma A, Driscoll P, Koolhaas JM, Bohus B (1992) Vasopressinergic modulation of stress responses in the central amygdala of the Roman high-avoidance and low-avoidance rat. Brain Res 596:35-40.

Sakai RR, He PF, Yang XD, Ma LY, Guo YF Reilly JJ, Moga CN, Fluharty SJ (1994) Intracerebroventricular administration of $\mathrm{AT}_{1}$ receptor antisense oligonucleotides inhibits the behavioral actions of angiotensin II. I Neurochem 62:2053-2056.

Shewey LM, Dorsa DM (1988) V1-Type vasopressin receptors in rat brain septum: binding characteristics and effects on inositol phospholipid metabolism. J Neurosci 8:1671-1677.

Skutella T, Probst JC, Engelmann M, Wotjak CT, Landgraf R, Jirikowski F (1994) Vasopressin antisense oligonucleotide induces temporary diabetes insipidus in rats. J Ncuroendocrinol 6:121-125.
Stoehr JD, North WG (1993) A physiological role for vasopressin in fear conditioning. Soc Neurosci $\Lambda$ bstr 19:594.1.

Thomas E (1988) Forebrain mechanisms in the relief of fear: the role of the lateral septum. Psychobiology 16:36-44.

Treit D, Pesold C, Rotzinger S (1993) Dissociating the anti-fear effects of septal and amygdaloid lesions using two pharmacologically validated models of rat anxiety. Behav Neurosci 107:770-785.

Uhlmann E, Peymann A (1990) Antisense oligonucleotides: a new therapeutic principle. Chem Rev 90:544-584.

Wahlestedt C. Pich EM, Koob GF, Yee F, Heilig M (1993) Modulation of anxiety and neuropeptide $\mathrm{Y}$-Y1 receptors by antisense oligodeoxynucleotides. Science 259:528-530.

Witt DM, Winslow JT, Insel TR (1992) Enhanced social interactions in rats following chronic, centrally infused oxytocin. Pharmacol Biochem Behav 43:855-861.

Zhao Q, Matson S, Herrera CJ, Fisher E, Yu H, Krieg AM (1993) Comparison of cellular binding and uptake of antisense phosphodiester, phosphorothioate and mixed phosphorothioate and methylphosphonate oligonucleotides. Antisense Res Dev 3:53-66.

Zhou L-W, Zhang S-P, Qin Z-H, Weiss B (1994) In vivo administration of an oligodeoxynucleotide antisense to the $\mathrm{D}_{2}$ dopamine receptor messenger RNA inhibits $D_{2}$ dopamine receptor-mediated behavior and the expression of $\mathrm{D}_{2}$ dopamine receptors in mouse striatum. $\mathrm{J}$ Pharmacol Exp Ther 268:1015 1023. 